\title{
RFID Data Loggers in Fish Supply Chain Traceability
}

\author{
Mira Trebar, ${ }^{1}$ Metka Lotrič, ${ }^{2}$ Irena Fonda, ${ }^{2}$ Anton Pleteršek, ${ }^{3}$ and Kosta Kovačič \\ ${ }^{1}$ University of Ljubljana, Faculty of Computer and Information Science, Ljubljana, Slovenia \\ ${ }^{2}$ Fonda.si d.o.o, Portorož, Slovenia \\ ${ }^{3}$ ams R\&D d.o.o, Ljubljana, Slovenia \\ Correspondence should be addressed to Mira Trebar; mira.trebar@fri.uni-lj.si
}

Received 15 April 2013; Revised 18 June 2013; Accepted 20 June 2013

Academic Editor: Iñigo Cuiñas

Copyright (C) 2013 Mira Trebar et al. This is an open access article distributed under the Creative Commons Attribution License, which permits unrestricted use, distribution, and reproduction in any medium, provided the original work is properly cited.

Radio frequency identification (RFID) is an innovative and well-recognized technology that supports all kinds of traceability systems in many areas. It becomes very important in the food industry where the electronic systems are used to capture the data in the supply chain. Additionally, RFID data loggers with sensors are available to perform a cold chain optimization for perishable foods. This paper presents the temperature monitoring solution at the box level in the fish supply chain as part of the traceability system implemented with RFID technology. RFID data loggers are placed inside the box to measure the temperature of the product and on the box for measuring ambient temperature. The results show that the system is very helpful during the phases of storage and transportation of fish to provide the quality control. The sensor data is available immediately at the delivery to be checked on the mobile RFID reader and afterwards stored in the traceability systems database to be presented on a web to stakeholders and private consumers.

\section{Introduction}

Consumers are more and more interested in receiving the information about the food they purchase and consume. They want to know more about the food composition, the origin of materials, the process history, and handling actions during the delivery. The main problem is how to control the food safety and quality with a traceability system in the production and distribution processes which the mandatory in European Union since 2002 [1]: “The food law aims at ensuring a high level of protection of human life and health, taking into account the protection of animal health and welfare, plant health and the environment. This integrated "farm to fork" approach is now considered a general principle for EU food safety policy." Furthermore, the document encompasses the importance of solutions that will fulfil all requirements: "It is necessary to ensure that a food or feed business including an importer can identify at least the business from which the food, feed, animal, or substance that may be incorporated into a food or feed has been supplied, to ensure that on investigation, traceability can be assured at all stages."
In a global environment it is very important to strengthen the food control to enforce risk-based food strategies and gain consumers' confidence. The EU project "RFID from Farm to Fork" (RFID-F2F) was funded by the European Union to demonstrate the use of radio frequency identification (RFID) in the implementation of an internet-based traceability system in the food and drink supply chain [2]. Several pilots were defined to maintain product and information flow upstream from the farm to the fork which enables the downstream query of information from the fork back to the farm [3]. Additionally, the cold chain analysis was based on temperature monitoring by RFID technology to improve the quality control.

Recently, many food traceability solutions and cold chain monitoring of temperatures are presented with the use of RFID technology, sensor, and wireless technologies. These systems are showing direct benefits in quality, safety of products, and supply chain optimization with fast product recalls of perishable food. Actually, one of the proposed real time monitoring solutions for cold chain distribution was using all three different technologies to meet the marketing 
requirements [4]. The results showed that retailers could use inventory and quality information for the promotion of products and prevent delivery of spoiled products to customers. Demonstrations of fresh fish logistics chain with RFID smart tag developed for real-time traceability and cold chain monitoring show important advantages in comparison to conventional barcode identification and monitoring methods [5]. The high frequency (HF) is considered as the best solution for the integration of foods with water conditions. RFID readers are operating at $13.56 \mathrm{MHz}$ with limited sensor tags, mobile and GPS which can automate the tasks and, have significant impact on stakeholders [6]. A transparent solution collects the temperature measurements in processing and reading distances of tags up to $1 \mathrm{~m}$ and USB connections to a host computer. Quality control, efficient storage, and transportation of frozen fish can also be well covered with RFID transport with the theoretical support to establish data integration network for food quality evaluation. Temperature monitoring systems are very important in fresh meat chain as a highly perishable product with a short-shelf life and are often designed with wireless sensor networks which can be replaced with RFID data loggers with sensors [7]. A holistic examination of temperature monitoring systems is presented with the objective of making an important contribution to optimal solutions in meat supply chains. Besides, the improvement of systems is based on the real time monitoring and decision support systems that can prevent damage of perishable food products during transportation [8]. The warning functions are based on RFID data and are used to set up an alarm when something unexpected occurs.

Nowadays, RFID technology is already recognised as a technology of many opportunities in food supply chain to improve the information flow and food safety. An overview of opportunities and constraints is reviewed to show the widen adoption of RFID technology in agri-food sector [9]. However, we can read about numerous pilot solutions, but the number of real applications is still limited due to various management or economic issues as the cost of devices and RFID tags is rather high and the benefits are not sufficiently recognised yet. Food traceability issues with barriers, technologies, performances, and many other attributes are very important for identification and implementation of an effective traceability system. About 74 studies were reviewed to highlight researchers on what they should focus on [10]. The most important are standardisation of data, integration of activities, technological aspects, strategies, and effective communication between stakeholders.

Very often, one of the issues connected to the distribution process of perishable food products, either fresh or frozen, is the increased temperature in trunks during the exposure to sun [11]. The importance of time-temperature control was recognised in the potential spoilage of food that can lead to the incidence of foodborne illness. The study presents guidelines about how to ensure food safety for consumers at home and also other stakeholders during the transportation. This is a good example of cold chain implementation with RFID data loggers to provide warning systems which are available on the internet or even on smart phones.
The main objective of the work is to explore the use of UHF semi-passive RFID data loggers in the traceability system of fresh fish supply chain. The analyses and evaluation results of RFID systems and temperature measurements in the pilot solution are used to represent the cold chain results to stakeholders. Additionally, the importance and some benefits of RFID technology are associated with experimental experiences. The paper is structured as follows. Section 2 presents the basic descriptions of RFID technology with hardware and software solutions, applications for control in the traceability system during logistics process. Several test results are discussed in Section 3 to introduce the benefits in the supply chain of the sea bass from processing room to retail and private consumer which is followed by the conclusion.

\section{Materials and Methods}

2.1. RFID Systems. The logistics process with warehousing of fish is performed by refrigerated vans transporting boxes and consists of three steps:

(i) the transport of boxes from processing room to the cold store,

(ii) keeping boxes of fish in the cold store during the night,

(iii) transport from cold store to the retail or private consumers.

RFID system in the ultra-high frequency (UHF), operating worldwide within the 860 to $960 \mathrm{MHz}$ band, is used. It consists of a fixed RFID reader and two antennas from the producer Impinj (Figure 1(a)); product name is "Speedway Revolution UHF RFID Reader-R420" [12]. It is designed, to perform identification in a traceability system of boxes, as an RFID portal with two actions (receiving, shipping) based on an external button. Three light indicators are added to determine the present status of the portal: white-portal is on; green-receiving; red-shipping.

Furthermore, the cold chain was implemented with two types of RFID readers.

(i) Fixed UHF RFID reader (Figure $1(\mathrm{~b})$ ): UHF reader (reading range up to $1 \mathrm{~m}$ ): ams AS3991 Low Power Evaluation Kit (ams AS3991 LP EVK) [13]. Reader is EPC Gen2 RFID integrated circuits incorporating physical layers of ISO 18000-6C. Adding a simple low-cost 8-bit microcontroller completes a highperformance Gen 2 reader for handheld and embedded RFID reader applications. Built-in programming options make it suitable for a wide range of UHF RFID applications. New AS3992 reader generation offers functionality of the previous AS3991 chip and is dedicated to operation on the DRM link frequencies used in ETSI and FCC region.

(ii) Mobile RFID reader Nordic ID Morphic (Figure 1(c)) is a mobile computer which offers EPC G2 UHF RFID reader in a compact form with an output power of a $100 \mathrm{~mW}$. Tags are typically read from a distance up to 


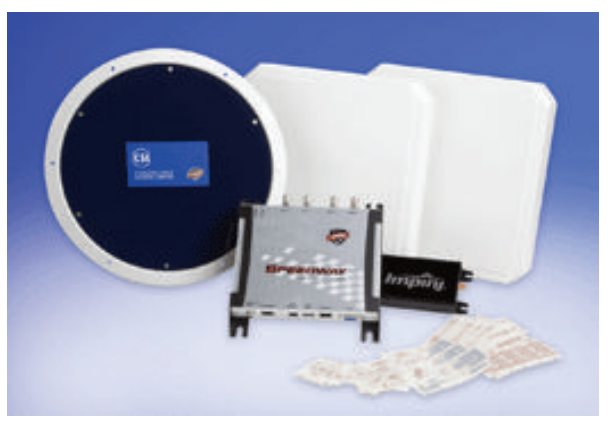

(a)

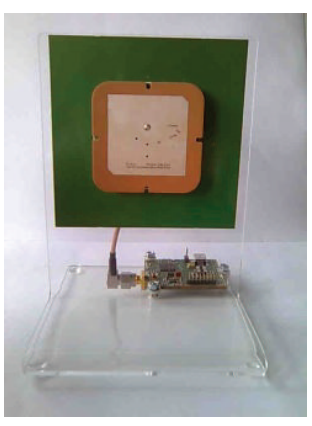

(b)

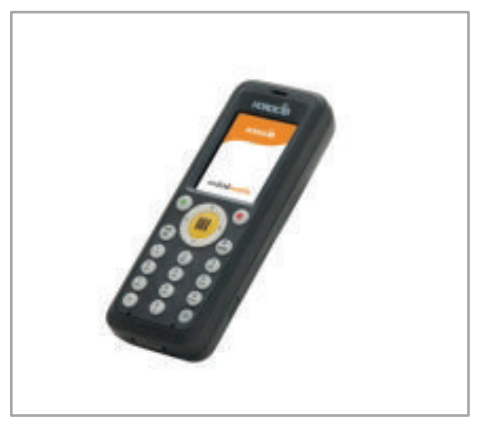

(c)

FIgure 1: (a) Impinj Speedway [12]; (b) ams AS3991 [13]; (c) Nordic ID Morphic [14].

$50 \mathrm{~cm}$ which is defined by manufacturer but can vary with the RFID tag type [14].

A prototype model of UHF RFID data logger is a semi-passive demo RFID tag as shown in Figure 2(a). The main module is SL900A chip, an EPC global Class 3 Gen2 compliant tag which is battery-powered smart label with cool-Log data logging commands [13]. Figure 2(b) shows the diagram of the chip dedicated to automatically track, monitor, time-stamp, and record information about any goods with shelf-life algorithm in the supply chain. The key features are the anticollision algorithm, the multilevel data protection, a smart power supply system and energy harvesting, and automatic sensors signal acquisition; programmable, scanning, and interrupt modes of data logging, a memory saving operation using multilevel limits selection, and innovative analogue nanotechnology architectures, based on low-leakage solutions. Chip supports logging data from an integrated temperature sensor with a typical nonlinearity of $\pm 0.5^{\circ} \mathrm{C}$ over the specified temperature range and from the two external analogue sensors. One of the most valuable features is the "interrupt triggered mode" on external sensor inputs that can be used for event-triggered logging, either from detecting the change of sensing parameter (the level of which is user defined) or from the external switch or microcontroller. At each trigger event the selected sensor values are stored. In addition to the sensor values, the realtime clock offset is also stored. Very important features of the smart label used in the described cold chain are temperature range $-40^{\circ} \mathrm{C}$ to $+125^{\circ} \mathrm{C}$, sensors measurement resolution 15 bit, temperature measurement accuracy $\pm 0.5^{\circ} \mathrm{C}$, frequency 860 to $960 \mathrm{MHz}$, battery supply $1.5 \mathrm{~V}$ or $3 \mathrm{~V}$, data logging from using on-chip temperature sensor and two external sensors, EPC Class 1 and Class 3 compliant, compatible with EPC Gen2, real-time clock for data logging, external sensor interrupt capability, serial peripheral interface, on-chip $9 \mathrm{~K}$ bit EEPROM, integrated dynamic shelf-life calculation, and advanced logging with 4 user-selectable limits. In additional to the Gen2 lock protection, the SL900A offers read/write protection using 3 password sets for 3 memory areas.

The analysis of RFID readers and RFID data loggers with temperature sensor (RFID-TL) was performed in the laboratory before the real implementation in the supply chain. The boxes of fish are made of Styrofoam; they contain the ice and also water when ice melts under higher temperatures. Furthermore, detailed tests of electromagnetic activities inside the styrofoam box were done to decide where to place RFID data logger. Several tests were performed to measure the maximum reading range of outside and inside the box, with and without ice. The position of RFIDTL regarding the reader is very important for handheld RFID reader with linear antenna which requires rectangular positions of RFID tag to be matched in polarization to obtain the best read range. It was acceptable to use the RFID reader for passive RFID tags and RFID data loggers with about $20 \mathrm{~cm}$ read range. The results show that the proposed RFID hardware could be appropriate for the purposes of a pilot. RFID temperature loggers and also RFID tags could be read through ice with Impinj reader [12]. Normally, many RFID tags attached to boxes were read as they pass near the reader antenna. For RFID-TL temperatures are read and checked in most cases by the delivery to the customer where they are removed from the box.

2.2. Fish Supply Chain. RFID traceability system was deployed in the northern part of the Adriatic Sea at the family owned fish farm [15]. The business process consists of complete supply chain of a very tasty, always fresh and high quality fish, "Piran sea bass." The main objectives of the fish pilot were the implementation of RFID technology as the "TRACK" function in the supply chain, including farm, processing, logistics and retail shown in Figure 3. The last step customer is also included but in the opposite direction as the "TRACE" operation to retrieve all the important information about the product.

A process of breeding sea bass from arrival of juveniles to the time of harvesting is monitored at the fish farm. The processing phase includes collecting orders, weighing, sorting, packaging fish into boxes, and applying cold chain control with aggregation of RFID-TL to the box. Each box is also labelled with RFID tag and printed information with QR (Quick Response) code and prepared for the transportation. After that, boxes are transported in the van to cold store and on the next day delivered to customers (retail, restaurants, supermarkets, and private consumers). At the delivery to the retail, RFID-TL is disaggregated from boxes which are then 


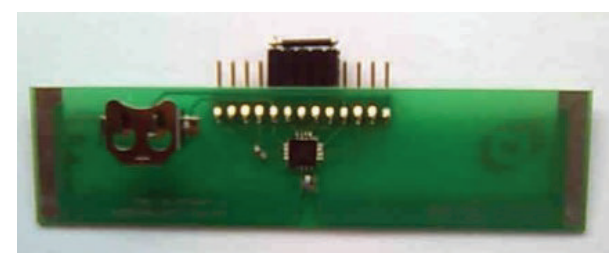

(a)

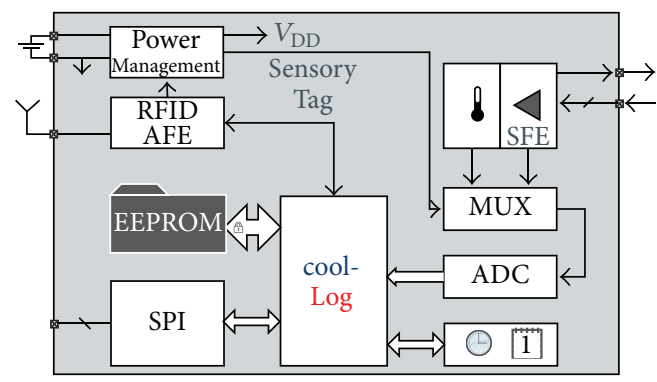

(b)

Figure 2: (a) The ams data logger-SL900A; (b) EPC Gen2 C3 single-chip data logger scheme [13].

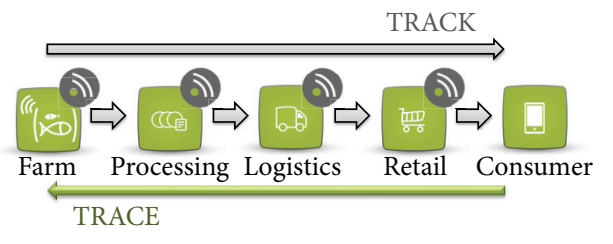

FIGURE 3: Fish supply chain.

placed in cold store until the fish is placed on the ice to be displayed for sale.

The use of RFID technology in supply chain is based on the standardized solution of EPC global network. The architecture is easy to use and it is easy to implement the mechanisms of the data interchange between servers, called EPC Information Services [16]. For the project GS1/EPC global format was selected which is currently used worldwide [17], is the format of choice when interacting with EPCIS, and allows to encode information suitable for business processes. The EPC (Electronic Product Code) uniquely identifies each single entity being traced. It is stored on the RFID tag and is a standard that defines EPC Gen2 tag data for products (GTIN_Global Trade Identification Number and SGTINSerial GTIN), EPC global Class 3 tag data for assets (GRAIGlobal Returnable Asset), and locations (GLN-Global Location Number). The unique identification is composed of three parts: manager ID, object class, and serial number which exactly specify traceable units.

2.3. Cold Chain. The demonstration of cold chain experiments is done with RFID data loggers with temperature sensor (RFID-TL). It is comprised of the following steps:

(i) RFID-TL initialization and Start Logging;

(ii) placement of RFID-TL in the box (aggregation);

(iii) identification of RFID-TL on the portal;

(iv) removal of RFID-TL from the box (disaggregation);

(v) Stop Logging and collection of temperature measurements.

Cold chain control was implemented during the pilot deployment in year 2012. Test scenarios were setup for the following options: (i) ambient temperatures when RFID-TL is placed on the box;

(ii) temperatures inside the box when RFID-TL is placed between or on the top of packed fish;

(iii) temperatures of the fish when RFID-TL is placed in the gutted fish which is covered with ice.

Figure 4 shows the logistic process with the control of temperatures that starts at the processing room in Seča when all orders are prepared for the transport. The boxes are placed into the van which delivers them to the cold store in Izola where the second phase of processing takes place. For customers that ordered gutted or fileted fish, the cleaning and packing processes are performed. After that all boxes are placed in the cold store. Next day, the boxes are delivered to the customers where the cold chain control ends, RFID-TLs are removed from the box, and sensors data is checked and uploaded to the traceability server.

The tests were performed on two types of packaging methods of fish in different boxes. An open white styrofoam box is used for retailers, restaurants, and supermarkets which buy larger quantities of fish that are completely covered with ice in the packing process. Another type of smaller boxes which are tightly closed is used for the delivery directly to customers at any location and ensures the required temperature conditions. The cold chain control is divided into three phases.

(i) Initialization of RFID data loggers is done in the processing room before the use. The mobile RFID reader is used to aggregate RFID data loggers with the box before their placement between the fish inside the box and outside the box. This is done before the box is filled with ice.

(ii) The identification of RFID data loggers is recorded on RFID portal in cold store to record their presence during the logistics process.

(iii) RFID data loggers are removed from the box at the delivery to the customer. They were disaggregated with the box, and temperature measurements were read and stored to the sensors database.

Figure 5 shows the first step in the cold chain process. Mobile RFID reader application reads the EPC code of RFIDTL (Figure 5(a)) and then the EPC code of a box (Figure 5(b)) 


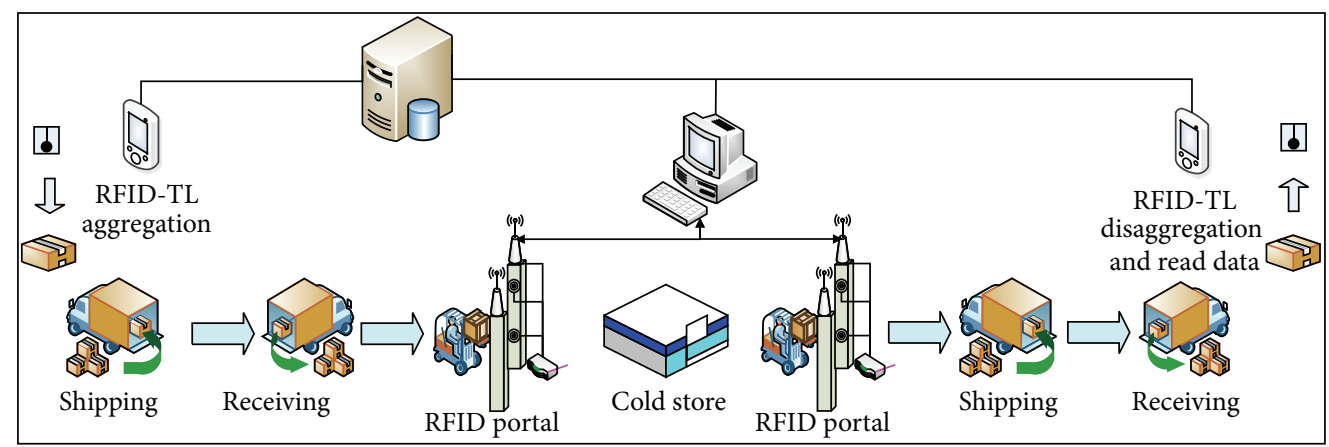

FIGURE 4: Logistics process.

to perform the aggregation of both codes in the EPCIS events sent to the database of traceability system.

In the next step, two RFID-TLs are placed in the white box to be used in the second step of the processing (Figure 6(a)) where three different options of measuring temperatures in the box are presented to analyse the results. We measured temperatures for two various ways where one RFID-TL is placed in the gutted fish (Figure 6(b)) and between the fish (Figure 7(a)).

Finally, the ice is placed on the fish to maintain low temperatures, the box is covered and closed with adhesive tape. Figure 7(b). shows how the second RFID-TL is attached to the box to be stored in the cold store. The fish box is after that transported to the cold store and on the next morning to private consumer where the process of disaggregation is performed, and RFID-TLs are removed from the box (Figure 8). A mobile RFID reader is used to generate events, to read temperatures from the user memory and to send data to sensors database. Furthermore, another application on mobile RFID reader supports the inspection of temperatures which gives the company immediate control of processes and handling conditions of delivery.

The initialization parameters of RFID-TLs were setup in advance on fixed RFID reader to use the same configuration in all tests. Log Interval for temperatures to be stored in the user memory was six minutes. Start Logging command was used at the beginning of each test to enable the cold chain control, and Stop Logging was used to stop recording temperatures.

2.4. Software Applications. Two applications were developed for the cold chain implementation to be included in the fish pilot: (i) initialization and examination of data for RFIDTL; (ii) aggregation of cold chain in the fish pilot. The third application on RFID portal was developed for the fixed Impinj Speedway reader [12] which was used as a part of traceability system and was also detecting the presence of RFID-TLs during logistics process with that application.

Initialization of RFID-TLs is performed on UHF RFID fixed reader [13] which is connected to the computer. The application is defined with a graphical user interface (GUI) to control initialization of each RFID-TL with constant specifications used in all tests. GUI is divided into two sections-the Tab section (current selected tab) and the Log section (communication data). Tab section consists of: (i) Settings-definition of RFID-TL parameters with start and stop logging; (ii) Plot-temperature graph.

The tab Settings (Figure 9) supports the following.

(i) Start Logging - set up of logging parameters and start logging temperatures.

(ii) Stop Logging-stop logging and storing temperatures.

(iii) Set Zeros-reset the user memory.

The predefined parameters for cold chain experiments in fish supply chain are as follows.

(i) Start Time: RFID-TL starts logging with Execute button (now).

(ii) Delay Time: 00:00 (no delay).

(iii) Logging form:

(a) Dense-all measurements defined with Log Interval are stored in user memory;

(b) Out of Limits-only measurements that fall out of specified limits are stored in the user memory;

(c) Limits Crossing-measurements that cross the limits are stored in the user memory.

(iv) Log Interval (MM:SS) - specifies the period between two temperature measurements.

(v) Sensor Enable-temperature sensor is enabled or disabled.

(vi) The last four parameters are used to specify limits with selected logging forms Out of Limits and Limits Crossing.

Afterwards, in the experiments with the predefined parameters only Start Logging is required before RFID-TL is placed in the box to measure temperatures of the fish during the transport and warehousing. Stop Logging is used at the end of the control process to have RFID-TL ready for the next test. 


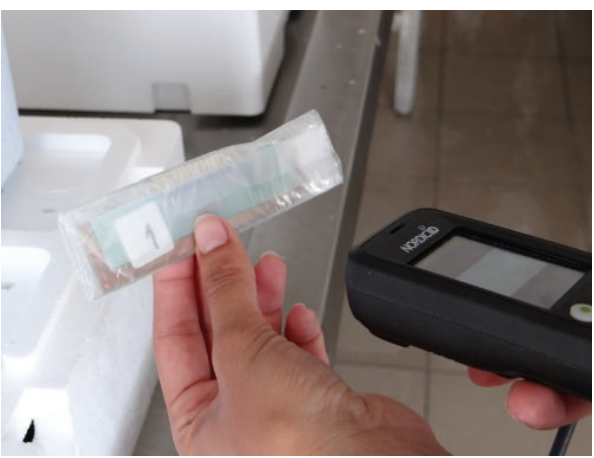

(a)

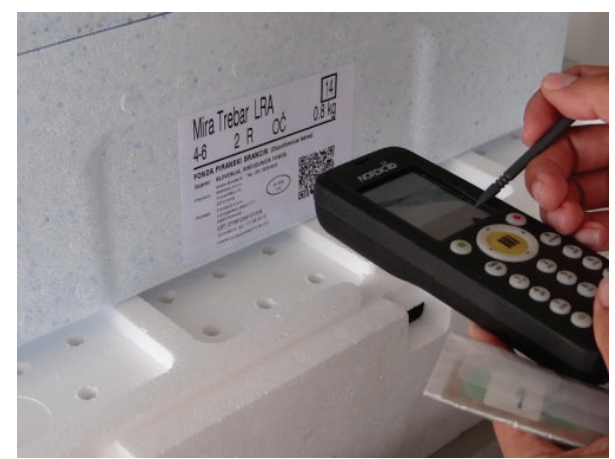

(b)

FIGURE 5: RFID-TL (a) is identified; and (b) aggregated with the box.

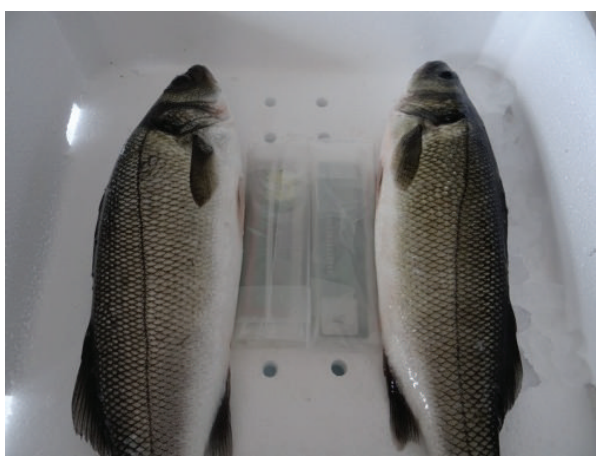

(a)

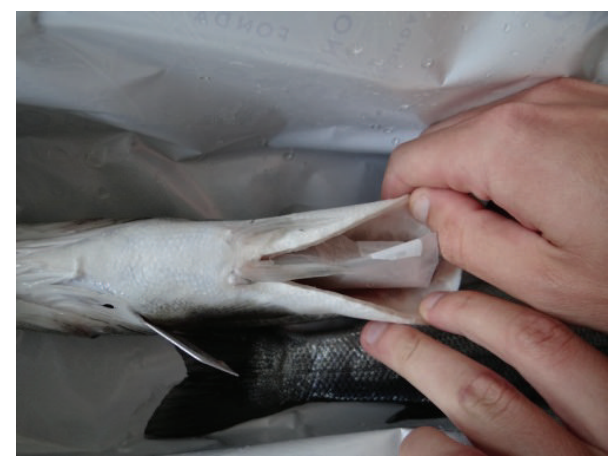

(b)

Figure 6: RFID-TL (a) in a box; (b) into the fish.

The tab option Plot shows the graph of temperatures stored in the user memory on RFD-TL. Furthermore, all initialization parameters with the number of temperature measurements and other parameters are shown in Figure 10. The temperature measurements can be exported in an Excel sheet to be used for further analyses.

The second cold chain application was designed on handheld RFID reader to define aggregations and disaggregations of RFID-TL inserted in the box. A simple GUI is used to perform reading of EPCs in two steps at the beginning and at the end of the cold chain activities. In the aggregation are first scanned EPC code of RFID-TL and after that EPC code of the box in which RFID-TL is placed. At the end, when disaggregation is performed a process of reading temperatures from the user memory on RFID-TL is added. In both cases, scanned EPCs are used as a part of pilot solution where data is uploaded to F2F project traceability server. Temperature measurements were also uploaded in the real time to the server and stored into sensor database. The results were used to realize all benefits from RFID traceability in the supply chain by identifying and tracking assets that performed cold chain control.

\section{Results and Discussion}

The UHF RFID monitoring system is affected by environmental conditions when RFID reader is used to read sensors data that was logged on RFID-TL during the logistic stage. Any conductive material or humidity may suppress the electromagnetic field strengths which affects the reading reliability. Possible solutions are multiple antennas placed in the area and using the DRM (dense reader mode) feature of modern readers [12]. Amplitude and phase (AM\&PM) demodulation is also a useful feature to eliminate communication holes through automatic I/Q selection and frequency hopping [13]. The Impinj reader was capable of reading EPC code and temperatures of RFID-TL inside the fish box when passing the cold store gate. The battery assisted logging function on RFID-TL does not need any electromagnetic field and is therefore unaffected by the environment. RFID-TL is removed at the end of the monitoring phase from the box and the data is read out in the "clean" environment.

Cold chain tests are part of the logistics phase in fish supply chain which comprises of the warehousing in cold store and transport of fish which is completed in two days. 


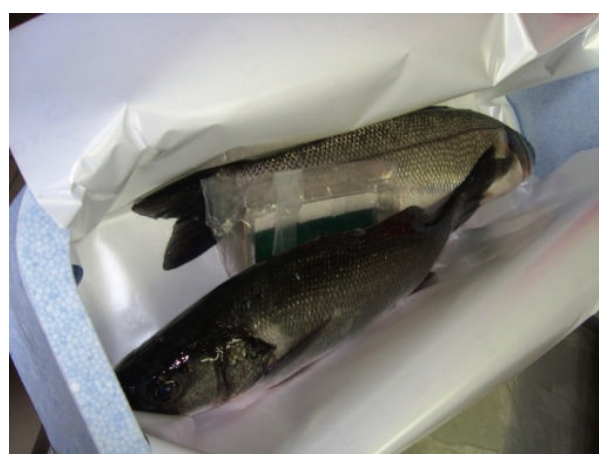

(a)

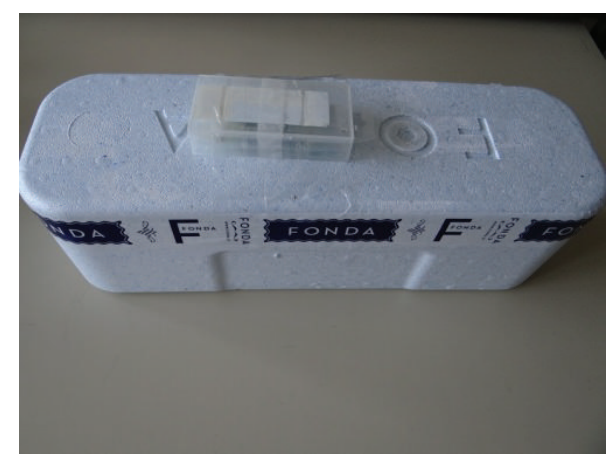

(b)

Figure 7: RFID-TL (a) is placed between the fish; (b) closed styrofoam box.

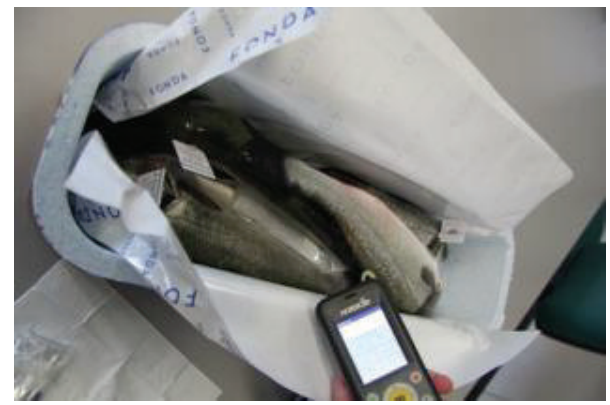

FIgURE 8: Read RFID data logger.

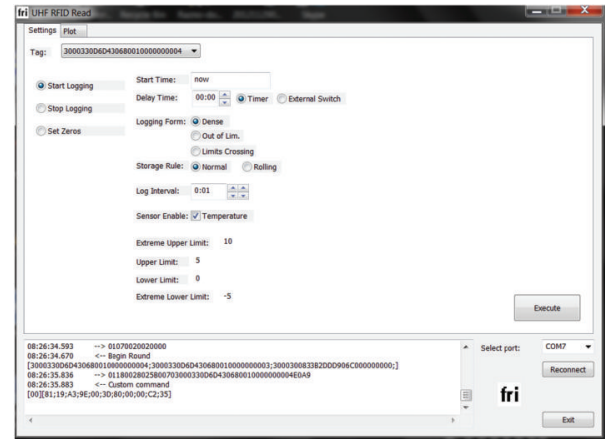

Figure 9: RFID-TL application-Settings.

Packed boxes are three times per week transported from processing room located in Seča to the cold store in Izola where they are stored over the night. Boxes are next morning transported from cold store to retailers, restaurants, supermarkets, and private consumers. The RFID implementation in cold store consists of the identification of boxes labelled with RFID tags and included RFID-TLs. Three automatic control functionalities are as follows

(i) shipping boxes from the processing room;

(ii) receiving boxes at the cold store;

(iii) shipping boxes from the cold store to customers.

The presented solution is implemented with RFID portal, placed on the cold store door and connected to the computer.

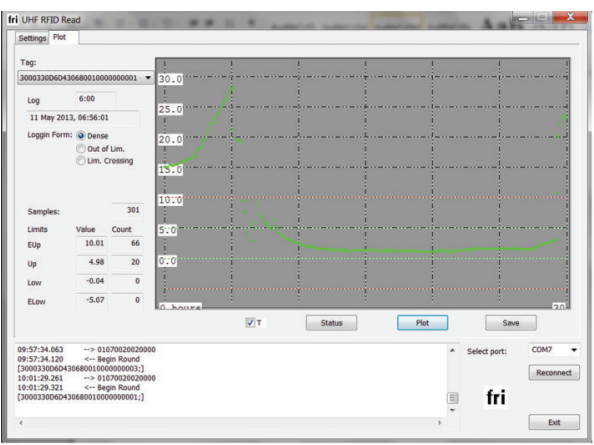

FIGURE 10: RFID-TL application-Plot.

RFID reader identifies each box with unique Electronic Product Code (EPC) which is stored in RFID label printed in the processing phase. Additionally, reusable RFID data loggers with sensors are added in the processing phase and removed from the box at the delivery to customers. Each device is also identified on RFID portal with unique EPC specified as assets by traceability standard and aggregated with the box EPC to link temperature measurements with the delivered box of fish. At each step, computer applications generate events to be uploaded to EPCIS repository on the server.

Several tests including monitoring of temperatures were performed during the evaluation of the traceability system to analyse the performance of RFID technology in fish supply chain. All applications were developed and programmed for the fish pilot deployment based on requirements of business processes. For RF communication of readers and tags low level protocol specifications were used. The data was stored in EPCIS based repository which was built on Fosstrak Open Source RFID Platform [18].

The results of two cold chain tests are presented in the graph (Figure 11) to analyse the temperatures for different placement of RFID-TLs which has an important meaning in interpretation of received results. The first test was done for the transport from Seča to Treviso. RFID data loggers were placed in the box between the fish to measure the temperature inside the box and on the box to measure ambient temperature. They were initialized on 23 April 2012 


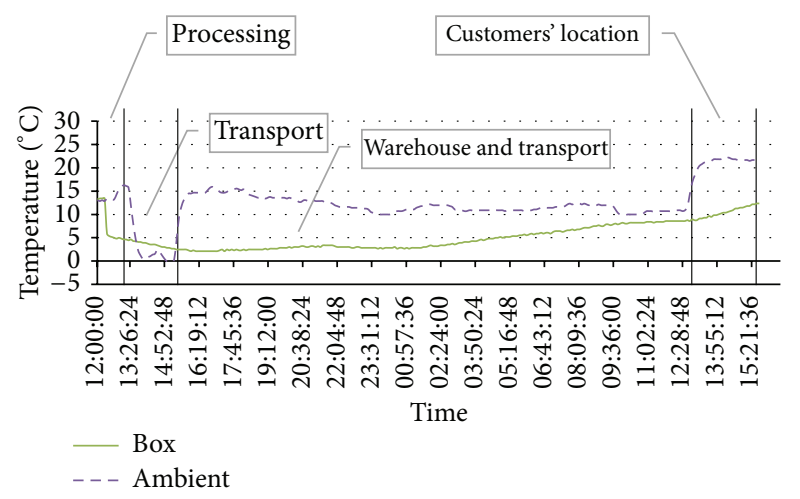

Figure 11: Temperature graph (Seča, 23.4.2012-Treviso, 24.4.2012).

before they were prepared with the fish order for the private customer to be sent to the home address. The delivery was made directly to the logistics partner in Italy where it was stored during the night and the next day delivered to the customer. Figure 11 shows the cold chain process with temperatures during the following.

(i) Processing-RFID-TL is close to the ice in the white box and temperature in the box very quickly reaches required temperatures between $0^{\circ} \mathrm{C}$ and $4^{\circ} \mathrm{C}$.

(ii) Transport-the box was transported in a cooled van by the company from Seča to the logistics partner in Italy. Temperatures in the van were very low, approximately $0^{\circ} \mathrm{C}$, and temperatures in the box decreased to the lowest temperature about $2^{\circ} \mathrm{C}$.

(iii) Warehouse and transport-the box was stored in the warehouse (cold store) with temperatures between $10^{\circ} \mathrm{C}$ and $15^{\circ} \mathrm{C}$ which caused the temperatures in the box to start increasing which is extended also in the last part when the box was transported to the customer.

(iv) Customers' location - when the box was delivered to the customer it was left in the room with higher temperatures between $20^{\circ} \mathrm{C}$ and $25^{\circ} \mathrm{C}$ which caused also faster rise of temperatures in the box.

The ambient temperature caused melting of ice, and temperature in the box has slowly risen. In this case it is very important the position of RFID logger where it measures the temperature.

The second test was analysed for the transport from Seča where the box was received at the laboratory in Ljubljana. RFID data loggers were placed inside the fish and on the box to measure ambient temperature. The logistics process consisted of the transport from processing room to the cold store in Izola and on the next morning to the customer. Figure 12 shows the cold chain process with temperatures:

(i) Processing 1 and transport-RFID-TL is placed directly under the ice in the white box and temperature very quickly reaches temperatures under $0^{\circ} \mathrm{C}$. During the transport in a cooled van from Seča to Izola the ambient temperature was also decreased.

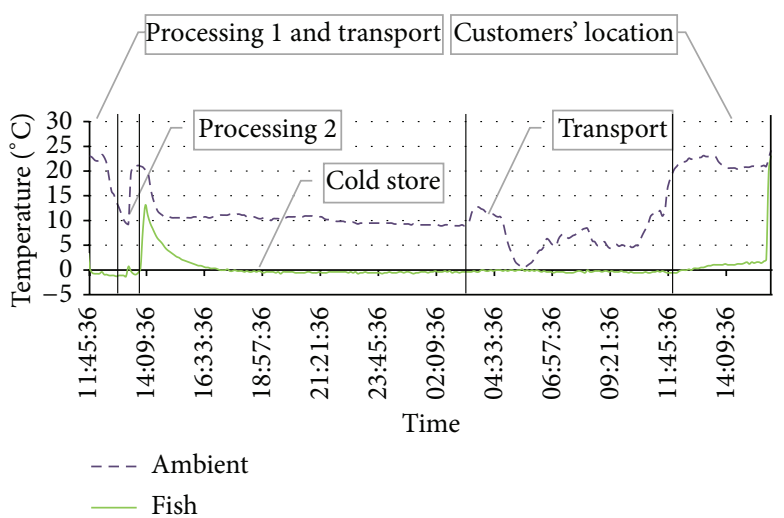

FigURE 12: Temperature graph (Seča, 7.6.2012-Ljubljana, 8.6.2012).

(ii) Processing 2-the RFID-TL was removed from the white box, the fish was cleaned, and temperatures in the room increased approximately up to $12^{\circ} \mathrm{C}$ before the fish was packed into the new box for the private customer where temperatures were decreasing again after the packing process.

(iii) Cold store-the box was stored over the night where the temperatures were around $10^{\circ} \mathrm{C}$. The temperature of the fish decreases and is all the time around $0^{\circ} \mathrm{C}$.

(iv) Transport-the delivery of boxes was performed on the next morning in a cooled van from coldstore in Izola to customer locations. Ambient temperatures vary when the boxes are prepared for the transport and when the van is opened during the delivery process. This doesn't have any influence on the temperature of the fish which is all the time constant around $0^{\circ} \mathrm{C}$.

(v) Customers location-when the box was delivered to the customer it was left in the room with higher temperatures, and temperatures of the fish continued to rise very slowly. The last temperature is recorded at the time of removing RFID-TL which caused the last measurement to be the same as ambient temperature.

The performance analyses of the hanheld RFID reader were done in real environment for aggregations and disaggregations where EPC code of one box and one RFID-TL were read one after another.

The proposed traceability solution and cold chain implementation in logistics and warehousing stage use the same technology based on UHF band which enables the use of the same hardware for two tasks which is not the case in [5] where high frequency RFID technology is used which is not compliant with GS1 traceability standard. According to the solution with sensor devices [8] and wireless sensor networks (WSNs) in our case these systems can be replaced with reusable RFID data loggers to save on the equipment cost. In comparison to other systems $[6,10]$, this paper presents an improved solution of item identification in the food supply chain which is upgraded with monitoring data. It is a standardised approach supported by GS1 organisation 
that includes all stages in the supply chain even if they are maintained with several partners. The most important benefit of this technology is the electronic collection of temperatures with data that can be shared worldwide. The implementation of cold chain requires reusable RFID data loggers with temperature sensors of $\pm 0.5^{\circ} \mathrm{C}$ accuracy. Additionally, the history information about the product will be supported by cold chain data and available to consumers.

\section{Conclusions}

The logistics phase of the food supply chain is very important to guarantee the food quality and freshness. The transport and warehousing of boxes were a part of the traceability system controlled by RFID readers at the end of processing and on the entrance door of the cold store with receiving and shipping processes. RFID portal performed identification of boxes and RFID data loggers that pass through the door. The results were used in other applications to verify customer orders.

The paper presented the analysis of cold chain as a part of traceability pilot performed with RFID technology from fish farm to consumers. The main elements and functionalities of such systems were evaluated, used in the fish supply chain, but they could be easily extended to other food sectors. Some drawbacks of the technology still exist due to the reason of high prices of RFID readers and passive tags when we are talking about small quantities of traced items in the supply chain. This is not the case with RFID-TLs which are reusable smart tags that could be successfully applied in the existing RFID system. Additionally, companies are not aware of the benefits, or they already have a barcode system which is working well.

The future work will be oriented towards the design and implementation of a monitoring system with RFID data loggers that supports shelf-life calculations and recognizes critical measurements that need to be examined.

\section{Acknowledgments}

This work has been supported by the European Commission (CIP-Pilot Actions), under the project "RFID from Farm to Fork" Grant Agreement no. 250444 and ARRS Program P20359 Pervasive computing.

\section{References}

[1] “Regulation EC/178/2002," http://ec.europa.eu/food/food/foodlaw/principles/index_en.htm, 2013.

[2] "RFID-F2F (RFID from Farm to Fork) project web page," http://www.rfid-f2f.eu/, 2013.

[3] I. Cuiñas, L. Catarinucci, and M. Trebar, "RFID from farm to fork: traceability along the complete food chain," in Proceedings of the Progress in Electromagnetics Research Symposium (PIERS '11) Marrakesh, pp. 1370-1374, March 2011.

[4] J. Shi, J. Zhang, and X. Qu, "Optimizing distribution strategy for perishable foods using RFiD and sensor technologies," Journal of Business and Industrial Marketing, vol. 25, no. 8, pp. 596-606, 2010.
[5] E. Abad, F. Palacio, M. Nuin et al., "RFID smart tag for traceability and cold chain monitoring of foods: demonstration in an intercontinental fresh fish logistic chain," Journal of Food Engineering, vol. 93, no. 4, pp. 394-399, 2009.

[6] J. Zhang, L. Liu, W. Mu, L. M. Moga, and X. Zhang, "Development of temperature-managed traceability system for frozen and chilled food during storage and transportation," Journal of Food, Agriculture and Environment, vol. 7, no. 3-4, pp. 28-31, 2009.

[7] V. Raab, B. Petersen, and J. Kreyenschmidt, “Temperature monitoring in meat supply chains," British Food Journal, vol. 113, no. 10, pp. 1267-1289, 2011.

[8] L. Wang, S. K. Kwok, and W. H. Ip, "A radio frequency identification and sensor-based system for the transportation of food," Journal of Food Engineering, vol. 101, no. 1, pp. 120-129, 2010.

[9] C. Costa, F. Antonucci, F. Pallottino, J. Aguzzi, D. Sarria, and P. Menesatti, "A review on Agri-food supply chain traceability by means of RFID technology," Food and Bioprocess Technology, vol. 6, no. 2, pp. 353-366, 2013.

[10] T. G. Bosona and G. Gebresenbet, "Food traceability as an integral part of logistics management in food and agricultural supply chain," Food Control, vol. 33, no. 1, pp. 32-48, 2013.

[11] S. A. Kim, S. J. Yun, S. H. Le, I. G. Hwang, and M. S. Rhee, "Temperature increase of foods in car trunk and the potential hazard for microbial growth," Food Control, vol. 29, no. 1, pp. 66-70, 2013.

[12] "Impinj Speedway," http://www.impinj.com/Speedway_Reader Evaluation_Kits.aspx, 2013.

[13] “ams R\&D d.o.o," http://www.ams.com/eng/Products/RF-Products, 2013.

[14] "NordicID Morphic," http://www.nordicid.com/eng/products/? group=3\&pid=33\#, 2013.

[15] "Fonda fish farm," http://www.fonda.si/, 2013.

[16] "EPC Information Services (EPCIS) Version 1. 0. 1 Specification," http://www.gsl.org/gsmp/kc/epcglobal/epcis/epcis_1_0_1standard-20070921.pdf, 2013.

[17] “GS1 Standards Knowledge Centre," http://www.gsl.org/gsmp/ kc, 2013.

[18] "Fosstrak Open Source RFID Platform," https://code.google .com/p/fosstrak/, 2013. 

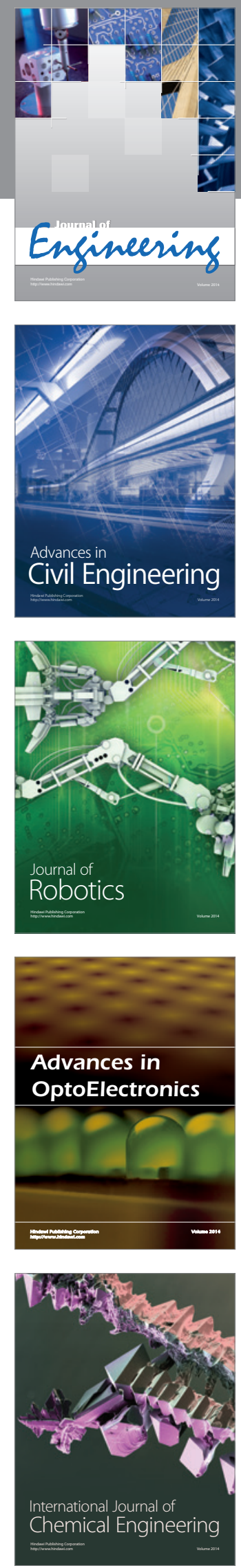

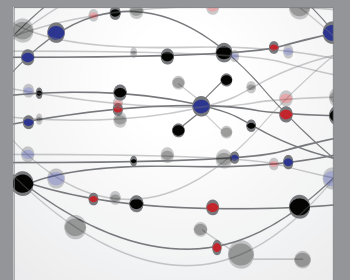

The Scientific World Journal
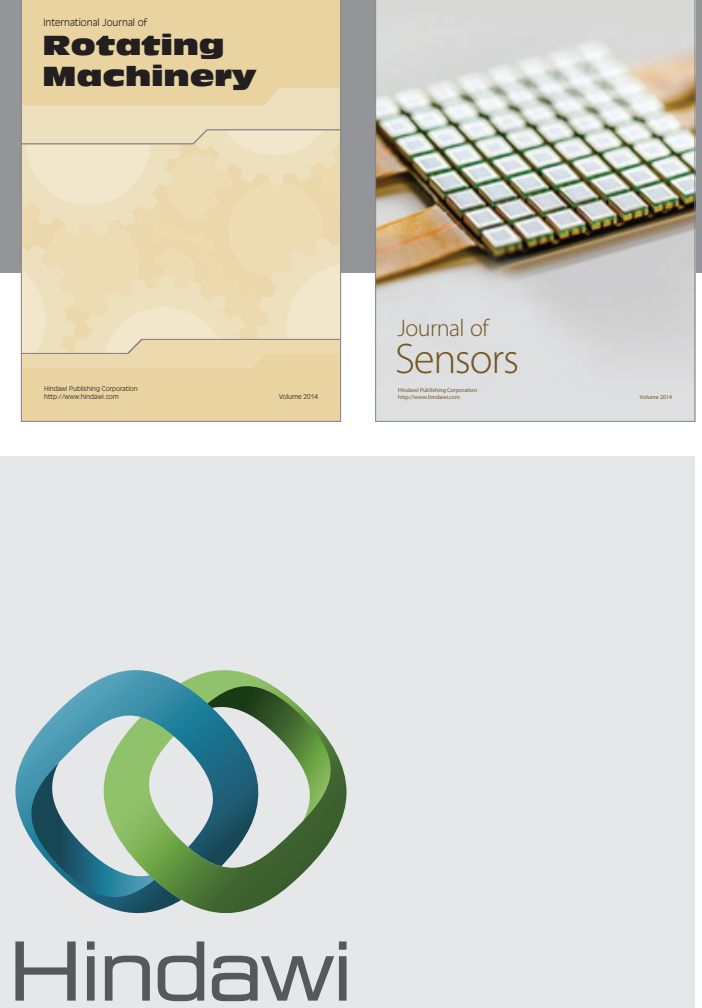

Submit your manuscripts at http://www.hindawi.com
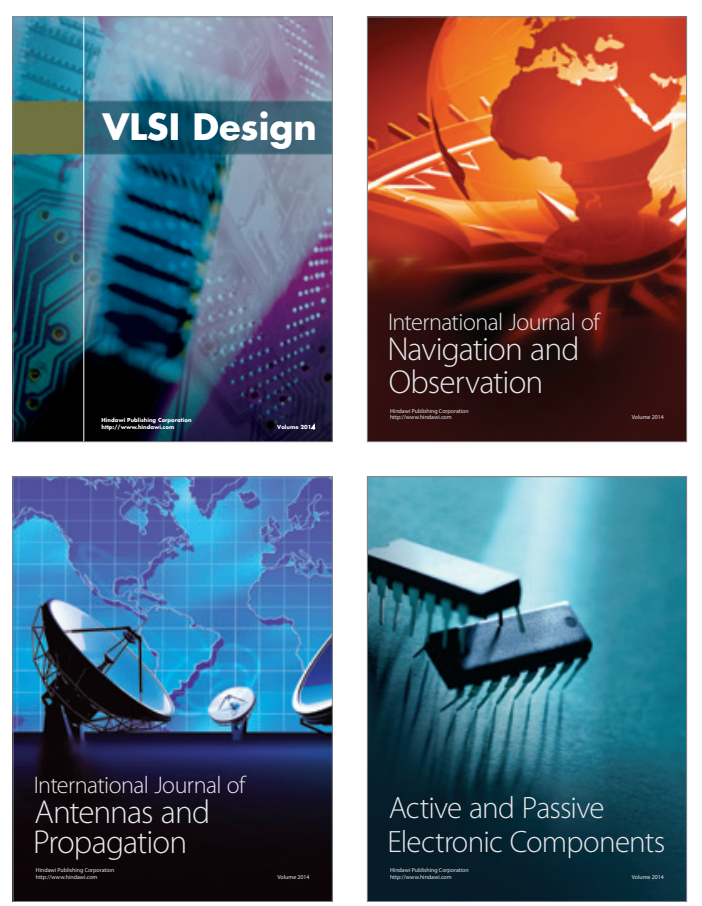
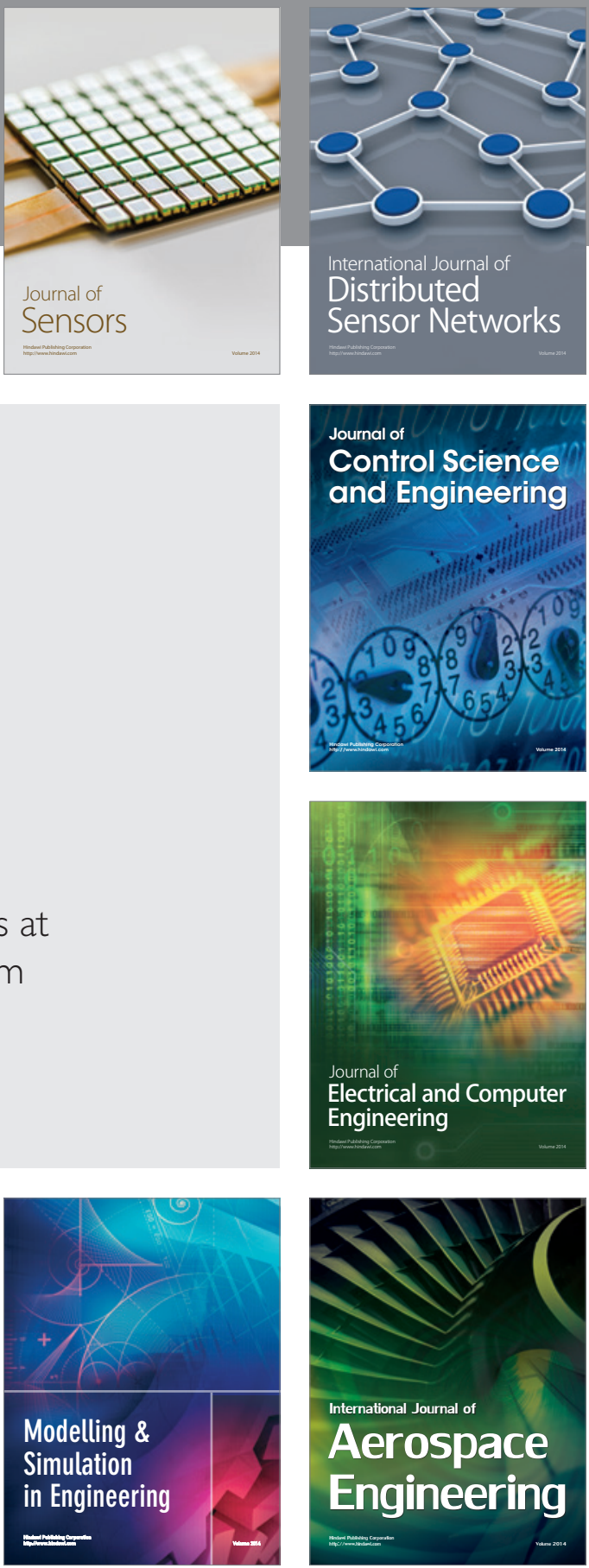

Journal of

Control Science

and Engineering
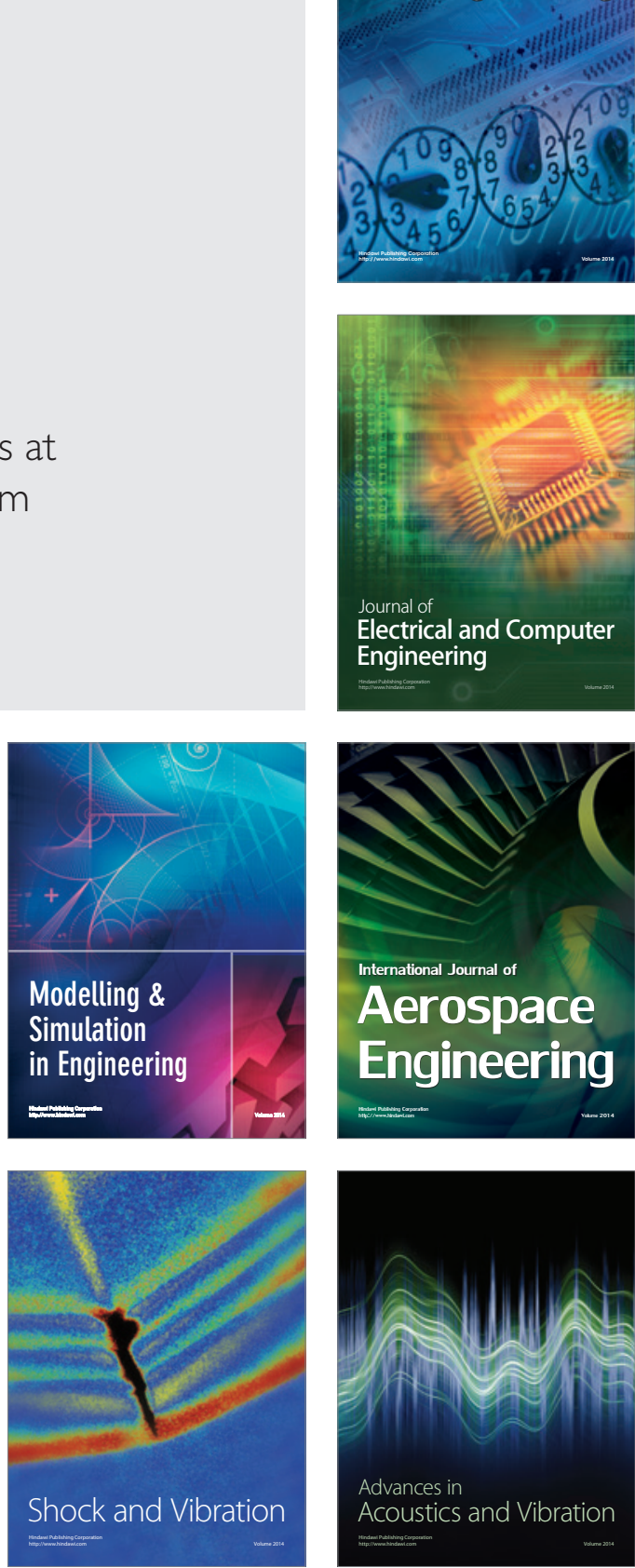